\title{
Catering for Socio-technical Transformations: Rethinking Technology Policy for Inclusive Transformation
}

\begin{abstract}
This chapter zooms out from looking at concrete pilot projects to looking more broadly at the implications of discussions on pilot projects as sites of politics. We discuss how such a perspective might feed into the work of innovators, funding bodies and the making of broader technology policy agendas. The chapter highlights the great potential in pilot projects as a mode of innovation for energy transitions, but bring to the fore the way such innovation activities often take on traditional and technology-centred characteristics. We argue that there is a need to change not only the ways that projects are funded to ensure diverse scientific participation. It is equally important to challenge the underlying assumptions and questions asked in pilot activities, as well as the goals of such energy transition activities. This entails a distributed agenda, where actors across the ecology of innovation share responsibilities for moving towards more just, democratic and humane modes of experimenting for sustainability.
\end{abstract}

Keywords Innovation policy $\bullet$ Innovation practice $\bullet$ Just transitions

In the previous chapters of this book, we have flagged the importance of pilot and demonstration projects as key activities in current energy and sustainability transitions. In this chapter we will zoom out from the projects and activities as such, to discuss a set of implications that follows from

(C) The Author(s) 2021 
the three earlier chapters. Our discussion focuses on three distinct sites where our earlier analysis in this book is of relevance. First, we will look at implications for the types of pilot and demonstration projects that we have studied in this book. Second, we will look at the institutional embedding of such projects, primarily by discussing the relationship between research and innovation funding and possibilities of doing things differently within current frameworks. Third, we will discuss more broadly some challenges for contemporary innovation, research and technology policy in working to produce pilot and demonstration projects that not only cater for technology development, but also seek to achieve what we broadly can call a more inclusive transition.

These three sites are closely interlinked, constituting a wide ecology of actors, organizations and technologies that shape and actively orchestrate the potential roles that pilot and demonstration projects take on in sustainability transitions. Our key argument in this concluding chapter is that while piloting and demonstrations hold great potential as a mode of innovation for increased sustainability, there is still a need for transforming such activities to make them more inclusive and more oriented towards broader collectives of actors. Observations highlighting that this should be the collective responsibility of a wide ecology of actors, also opens for diagnosing contemporary innovation policy and suggests the development of somewhat different policy measures than those that are usually prescribed for improving innovation for sustainability.

\section{Transforming the Innovation Practices of Pilot Projects}

Through this book, we have argued that pilot and demonstration projects are a central mode of innovation for realizing many climate and sustainability ambitions. Beyond this, we have suggested that such projects are political entities: they do not only discretely change technological systems; they are potentially transformative for societies more broadly. This is one of the reasons why a reflective approach to participation is important, not as a matter of securing social acceptance for new technological configurations, but rather as a matter of securing legitimacy and opening up the issues within and around such projects to forms of democratic governance.

In this book, our discussions have primarily circled around innovation within the field of smart energy technology and electromobility. While our 
discussions have illustrated diversity on behalf of pilot and demonstration projects in terms of the degree of engaging socio-technical complexity, such projects also tend to re-produce what Chilvers et al. (2018) describe as dominant participatory collectives. In Chap. 3 we discussed participation as an orchestrated phenomenon (Skjølsvold et al. 2018). Keeping with this metaphor, we might say that the actors who set up and establish pilot projects tends to orchestrate participation either as a form of consumption, that they seek participation though igniting behaviour change or that they open for participation in the form of consultation.

On the one hand, participation orchestrated in these dominant ways limits potential transition agency on behalf of various publics, keeping it within well-defined and previously established roles that do not necessarily challenge the non-sustainable traits of contemporary societies. On the other hand, the technologies also tend to be framed relatively modestly, in the sense that the impacts of technologies are discussed in very narrow terms. As an example, experimenting with demand side management or demand-response technologies tends to be understood as very discretely relating to energy demand and its potential flexibility, in such a way that social agency is reduced to consumption (Wallsten and Galis 2019; Throndsen and Ryghaug 2015). Such technologies, however, have much broader potential social implications. From a critical perspective they might feed into social processes of re-producing energy poverty, traditional gender roles and other forms of inequalities (Suboticki et al. 2019; Powells and Fell 2019), but there are also examples of such technologies becoming catalysts of what we have called energy citizenship (Ryghaug et al. 2018).

Hence, we are faced with a situation in which many pilot and demonstration projects within smart energy and electro mobility mobilizes a very narrow conception both of what technology can do, and of what its social implications are. This is a paradox, because smart energy technologies tend to be part of elaborate visions not only of small energy system demand-side changes, but also of broad energy system and society wide transformation (see e.g. Strengers 2013; Goulden et al. 2014; Skjølsvold 2014; Ballo 2015). Such visions are sometimes formulated by scholars, but just as often circulate through the rhetoric of policy and industry. A prominent example of this is the EU strategic energy technology (SET) plan and its integrated policy roadmap, which state that activating and engaging consumers is a chief energy policy challenge in the EU for the 
coming years. Why are such sentiments not well reflected in the innovation practice of most pilot projects?

From our perspective, a key part of the problem at hand is that pilot and demonstration projects within smart energy technologies and electro mobility often have very clear technological goals, or what Weiland et al. (2017) call 'target knowledge'. Examples can be the integration of new renewable energy technologies or the balancing of supply and demand in the electricity system. On the other hand, the social goals, or social target knowledge tends to be formulated weakly, for instance as an abstract and non-specific idea of becoming flexible energy users or more active consumers.

Thus, a key challenge for innovators who engage in the production of pilot and demonstration projects is to symmetrically develop both social and technical target knowledge associated with their projects. Over the last decades, the social sciences and humanities have produced a vast repertoire of potential forms of social target knowledge (see. e.g. Ingeborgrud et al. 2020; Sovacool 2014; Sovacool et al. 2020). Examples are manifold and rich within the literature on energy justice (e.g. Jenkins et al. 2018), where there has also been developed specific normative analytical categories for smart energy technologies, such as the goal of achieving flexibility justice (Powells and Fell 2019). To us, then, a key question remains: Why is target knowledge most often deeply anchored in very specific technological goals and seldom formulated in terms of visions about social factors and future societies? Why has it become common sense for research projects to highlight the need for technological progress within rather limited and narrow technological areas and to a lesser extent fund research that follow up on the societal transitions needed in order to meet future societal goals such as low carbon societies and sustainable living? Later in this chapter, we will relate this strongly to the role of funding agencies, but for now, we will continue to probe the logics within projects.

\section{The Challenge of the Social: Socio-Technical Asymmetries in Pilot and Demonstration Projects}

Through decades of studies on design processes, scholars from STS have illustrated that technology developers mobilize insights, or imaginations of technology users as key resources in design and innovation processes (e.g. Woolgar 1990; Akrich 1992; Oudshoorn and Pinch 2003). Our 
discussions in Chaps. 2 and 3 illustrate that the same is true within smart energy technology and electromobility (see e.g. Skjølsvold and Ryghaug 2015; Ryghaug and Toftaker 2016). Those who develop pilot and demonstration projects like those we have discussed, often do so either though imagining themselves as the ideal users of their own technologies (Strengers 2013,2014 ), or through imagining technology users as a potential hurdle which should ideally be bypassed through clever design or automation (Fjellså et al. forthcoming; Skjølsvold et al. 2019). We will return to questions concerning the role of funding mechanisms later.

At this point we will note that there is a gap between the rhetoric of European policy, and the practice of many pilot projects, where policy rhetoric points towards ambitious social target knowledge while this is not always followed up in practice. From our perspective this is both disappointing and a missed opportunity. In practice, such asymmetries can take on many forms. In some instances, demonstration projects might masquerade a pure focus on technology with rhetoric on user involvement and user centric design in order to please funders or other external stakeholders that have attempted to orchestrate the participation of technology users as co-designers. To provide one example, this was observed in a large European interdisciplinary research and innovation project (Skjølsvold and Lindkvist 2015) where the technological goals of the project were clear; while leaving other goals in the dark. On the one hand, the project sought to verify technically that households in Italy and Germany were in principle able to produce as much electricity as they needed from newly installed solar panels. However, actors within this project had identified the mismatch between production and demand from solar power as a challenge, and hence intended to implement smart energy management as a way of exchanging electricity between buildings in a neighbourhood, in order to ensure that supply and demand were matched.

The project flagged ambitions of such neighbourhoods becoming entities of sharing and collaborating, hence quite clearly articulating a set of socially oriented forms of target knowledge for the pilot project. Given our discussions on material participation and energy citizenship in Chap. 3 (see also Ryghaug et al. 2018), one might intuitively consider this project as one that, on the one hand, tested a set of new technologies, while, on the other hand, using that technology to raise a set of public concerns or issues, allowing for new forms of collaborative participation in transition activities on behalf of the involved households. This might comprise a quite radical orchestration of public participation through smart energy 
technologies. As a way of achieving these quite ambitions social targets, the actors behind this project formulated ambitions of co-designing the involved smart energy technologies together with the prospective technology users of the project.

If taken at face value, this large European project involving several demonstration sites, explicitly relied on users participating as designers to achieve success. In practice, things looked different. From the start, the involved researchers and innovators were very sceptical towards involving users in real design and development activities. The scepticism was often rooted in questions concerning whether users really could understand such complex technologies in ways that made it possible for them to participate in technology design exercises. Through a gradual process, the goals of co-design were dismissed in practice. The rhetoric of co-design remained, however, and a form of co-design workshops was conducted. No actual users were invited to these workshops, and instead, project engineers acted as users themselves. This was justified by the fact that in principle, they could very well become future users of the technologies they were developing.

This story serves to illustrate that while the social aspects of many energy pilot and demonstration projects today makes up a much larger share of the narratives of such projects, these narratives do not necessarily reflect actual project practice. On one level, this might reflect a status gap in the relationship between social and technical knowledge within such projects (Ingeborgrud et al. 2020). Just as important, however, is probably the relationship between individual projects such as this, and their funders. Gram-Hanssen and Darby (2018) point out that funders who ask for citizen participation and engagement tend to do so quite vaguely, and in ways that open for purely tokenistic acts of inclusion. A possible interpretation of this, building on the work of Colette Bos et al. (2014), is that European science policy and funding mechanisms tend to cyclically mobilize new terms within their documents, without necessarily imposing strong sanctions on actual science and innovation practice. In what follows we will dive deeper into the relationship between funding and innovation practice, and potential consequences for citizen participation and inclusion. 


\section{The Orchestration of Research and Innovation Through Funding}

Over the last pages, we have critically discussed some traits that we find problematic in many contemporary pilot and demonstration activities. Keeping with a perspective where we see transitions as enacted by a wide array of actors, changing this situation is not the sole responsibility of individual researchers or consortia. Changing the dynamics of the way research and innovation is conducted and the logics of such activities are also, of course, a form of socio-technical and multi-level transition. As we discussed in Chap. 1, the dynamics of such transitions entails work amongst a wide array of different actors engaged and embedded in various contexts. It also takes time.

As we hinted at in Chap. 2, access to research and innovation funding is a key resource mobilized in the making of pilot and demonstration projects. Such funding is often a way for authorities of different kinds to enact innovation, climate, transport or energy policy. An example of this is the Norwegian government's efforts to implement "National centres for environmentally friendly energy" (called FMEs), which was a direct consequence of a cross parliamentary political agreement on how to tackle climate change. The outcomes were a series of long-term funded research centres, of which the vast majority have been technological in character. The explicit mandate was to engage in value creation and innovation within green energy technology in close cooperation with industry. This is a funding mechanism with some similarities to those of UK Energy Research Centre (UKERC) and other similar UK-based initiatives (Winskel 2018). A key activity across the Norwegian FME centres was the setting up of pilot and demonstration projects. As Schot and Steinmueller (2018) have highlighted it is very difficult to assure that such efforts go beyond classical technology-oriented pilots. Hence, this is one example of how governments work to orchestrate the work of researchers and technology developers, where the outcome quite predictably was the formation of a set of large consortia which primarily engages in classical technology development activities.

On a basic level, the Norwegian example of centres for environmentally friendly energy reflects scholarship highlighting that in pure shares of funding, the social sciences are vastly inferior to the technical and natural sciences within climate and energy research (e.g. Øverland and Sovacool 2020; Foulds and Robison 2018). Yet, our argument here is not that 
funding more social science would necessarily enable more radical and socially oriented target knowledge in future pilot and demonstration projects. Such projects are shaped not only by the funding but also by the underlying assumptions concerning the character of innovation, the character of human rationality and the roles that technologies are expected to play in future societies. This has been illustrated repeatedly in research on smart energy technologies (Skjølsvold 2014; Ballo 2015), and recently these dynamics have also been shown in analyses of specific funders (Foulds and Christensen 2017).

Through our discussions in Chaps. 2 and 3, we have seen that many pilot and demonstration projects rely on funding from the European Union, and specifically from Horizon 2020, which over the last years have been the key framework programme for supporting research and innovation within the EU. Within the domain of energy, European research and innovation funding has arguably marginalized research on demand side technology use and citizens at the expense of a focus on energy production technologies (Wilson et al. 2012; Foulds and Robison 2018). The increased focus on "accelerated energy innovation" that has become a prominent aspect of energy policy-making in response to more urgent need for change have probably also contributed to this development, as focus has been directed towards cost reductions and deployment support as well as a central role for the private sector and public-private partnerships in transitions (Winskel and Radcliffe 2014).

More recently, however, "active consumption" has become one of the pillars around which projects from this framework programme is funded, and indeed, from the sorts of pilot and demonstration projects we discussed in Chaps. 2 and 3 it is clear that there is often a focus on changing what happens at the demand-side of the energy system. An important question for us, then, is why this apparent turn in the logics of European research and innovation funding has not resulted in much clearer formulations of social target knowledge within pilot and demonstration activities across Europe?

Foulds and Christensen (2017) have provided some important clues, in their analysis of the assumptions that underpin funding of energy research in the Horizon 2020, and specifically the ways that this program conceptualizes the relationship between social and technological development (see also Foulds et al. 2019). According to these scholars, the energy working programme is firmly rooted within a techno-economic paradigm, which rests on a dual conceptualization of human agency. On the one 
hand, people are primarily understood to act in the capacity of being rational consumers of energy, which results in a focus on behaviour change, decision making and choice, in other words well within what Chilvers et al. (2018) refer to as 'dominant modes of participation'. The key strategies for making consumers more active include raising awareness and providing information (see also Throndsen and Ryghaug 2015). On the other hand, people are conceptualized as a potential non-technical barrier to the diffusion of new technologies (see e.g. Skjølsvold 2012; Eaton et al. 2017). Hence, citizens are, on the one hand, seen as enablers of the transition through active consumption, while on the other hand being considered a barrier through resisting and rejecting new technologies. Thus, Foulds and Christensen's (2017) policy analysis clearly reflects the tension earlier described and identified within one single project (Skjølsvold and Lindkvist 2015).

A similar story can be told about the transport domain. Here, a key mechanism for the EU's goal to diversify and strengthen energy options for sustainable transport is through the Strategic Energy Technology (SET) Plan that sets out to increase energy efficiency and speed up the decarbonization of the transport sector, mainly by boosting research and innovation. Two key actions are put forward for this: (1) Action 7becoming competitive in the global battery sector to drive e-mobility forward; and, (2) Action 8-strengthening market take-up of renewable fuels needed for sustainable transport solutions (European Commission 2017; Ryghaug et al. 2019). Hence, the goals are purely technological, with the social world being reduced to "market uptake". Hence, this policy disregards the vast body of socio-technical knowledge on the diverse and comprehensive processes that are needed across transport and mobility systems to achieve the needed societal transition (Hopkins and Higham 2016; Suboticki et al. 2019).

All of this means that the way participation is orchestrated in individual projects is no coincidence. Contrarily, the orchestration of participation is tightly linked to broader repertoires of understandings of human rationality and technology diffusion that circulate through networks of policy makers, funders and research scholars. While there has clearly been an expansion in focus in terms of opening for energy research and innovation projects that includes a focus on people and human action, the types of questions asked, the goals formulated and the technologies developed still appear to be restricted and confined to them being embedded in a rather tight and limiting techno-economic paradigm. The result is, on the one 
hand, a quest to optimize current patterns of energy consumption and production, rather than questioning the logics residing behind such patterns and seeking radical alternatives. Further, funding mechanisms and call texts give little room to ask questions that either do not concern how to optimize behaviour or how to diffuse the production and deployment of new technologies.

\section{Re-Thinking Transformative InNovation in Inclusive, Material and Human Terms}

Our discussion above points to a relationship between the making of pilotand demonstration projects, and the ways that such projects are often funded and anchored in institutions that operate based on narrow definitions of human rationality and technological development. If we are to return to the language of the multi-level perspective (MLP) as discussed in Chap. 1 (e.g. Geels 2002), we might say that many of the developments emerge from within a regime of research and development, where these definitions and understandings of human behaviour and technological development are integral aspects of these regimes semi-coherent grammar or rule-set. Keeping with this perspective, this means that the changes emerging from such endeavours are likely to be incremental rather than transformative.

The sorts of criticisms that we have discussed above have deep roots in decades of work at the intersection of social sciences, technological sciences, natural sciences and innovation studies. During the 1990s, Constructive Technology Assessment (e.g. Schot 1992; Rip et al. 1995) was put forward, as a framework where social scientists would work as mediators, bridging separate worlds, and through this addressing societal concerns emerging around scientific practice and innovation activities. In the same period, scholars within STS (e.g. Gibbons 1994) advanced ideas of context sensitive, problem focussed and interdisciplinary research under the banner of 'mode 2 science' or socially distributed knowledge (Nowotny et al. 2013). Others flagged the merits of research incorporating values such as unpredictability, incomplete control and a plurality of legitimate perspectives as a response to emerging challenges such as climate change, often described as 'post-normal science' (Funtowicz and Ravetz 1995). 
The acronyms ELSI and ELSA were also put to work during the 1990s, as a way of dealing with ethical, legal and social implications/aspects, mainly of the life sciences, genomics and associated innovation. While they became thematically significantly expanded over the years, these programs have also become criticized for maintaining quite narrow conceptualizations of relevant issues rooted in ethics and risks, while overlooking more fundamental and systemic issues such as global justice and environmental issues (Zwart et al. 2014).

Later, related ideas have been promoted under the banner of Responsible Research and Innovation (RRI) (Von Schomberg 2013; Stilgoe et al. 2013), where the goal has been to build anticipatory, inclusive, reflexive and responsive practices of science and innovation. Both ELSA and RRI have strived to increase collaborations between social scientists and researchers and innovators from the technical and natural sciences. While many scholars promoting such perspectives flag far reaching ambitions on improving the conditions for how to govern emerging technologies, both approaches have been criticized of being institutionalized mainly as hedging mechanisms, where discussions about social and ethical aspects of technology early in innovation processes is expected to secure acceptance and reduce resistance to the end products of innovation processes (e.g. Zwart et al. 2014).

With a basis in challenges such as climate change and sustainability, recent years have seen the emergence of much critical debate about contemporary innovation systems. Johan Schot and Laur Kanger (2018) have suggested that the dominant rules and Meta rules that have guided the last 250 years of modernization might be fundamentally at odds with achieving key sustainability goals. The role of science and technology within this process has been framed either as a vehicle of economic growth to enable mass production and consumption, or as input factor to national innovation systems that strive to produce domestic growth in a globally competitive landscape. Such systems have produced economic growth, but also the double challenge of environmental degradation and social inequality (Schot and Steinmueller 2018). As an alternative, they call for a new and transformative innovation policy, which starts from the assumption that "innovation cannot be equated with social progress, even when corrective social policies are in place" (ibid., p. 1562). This claim is made based on the observation that many high-tech developments fuel rising global inequalities and rests on assumptions of increased growth and natural resource degradation. 
For these scholars, the sustainable development goals (SDGs) constitutes a set of challenges so fundamentally different from the challenges solved through technological innovations in the past, that one should challenge the notions that industry transformation or technology transition is enough. Instead, the notion of transformative innovation policy suggests that one should actively seek socio-technical system transformation. As an example, the authors use the systems of transportation. Here, the role of science, technology and innovation policy within ordinary innovation systems would be to improve battery capacity in order to electrify new domains of transportation. In this case, one could end up transforming industry structures to some extent and reducing direct $\mathrm{CO}_{2}$ emissions, but one might not realize the SDGs. Instead, Schot and Steinmueller argue that innovation policy should be mobilized to:

[...] Supporting the emergence of new mobility systems in which for example private car ownership is less important, other mobility modalities such as small taxi vans, public transportation, walking and bicycling are more used in combination with for example electric vehicles provided by types of companies dedicated to the provision of mobility services using ICT capabilities. In this new system, mobility planning and thus also reduction of mobility has become an objective of all actors, and even a symbol of modern behavior. (Schot and Steinmueller 2018, p. 1562)

Hence, they foreground social innovation, the need to explicitly formulate social goals rooted in notions of justice, to go alongside technological goals. This entails expanding on who is involved in innovation and highlighting that citizens, NGOs and marginalized groups should play active roles. A key element of their argument is that producing such an innovation system would not only entail formulating a new policy for innovation, but also opening for and cultivating spaces of contestation and politics. These politics would be founded on spaces of experimentation, societal learning, public debate, deliberation and negotiation, which would be impossible without broad societal participation.

Presently, there is a stream of scholarship which resonates well with these ideas, calling for increased attention to what such an inclusive and transformative form of innovation policy and politics might entail in practice. We find this encouraging, because these literatures target the sorts of tensions highlighted in Chap. 1, where we argued that studies rooted within the MLP have had a tendency to focus quite narrowly on 
technological innovation and diffusion, while studies emerging from STS have arguably had a broader focus on the role of technologies in society. An example, is Jenkins et al. (2018), call for stronger inclusion of ethics and justice, both within socio-technical analysis of transitions, and in policy making in order to make unfolding transitions more just. Further, Delina and Sovacool (2018) point to the merits of plurality and diversity both in terms of recognizing scientific insights across technical, natural and social sciences, and within organization and decision making in their call for more human and just transitions. Valkenburg (2020) notes that calls for plurality of voices in innovation governance tends to result in a focus on forming consensus but argues that a contestation-oriented order might be equally fruitful. Jenkins et al. (2020) have further formulated an agenda which, on the one hand, points to the scholarly merits of energy justice, and on the other hand, also targets the institutional landscape of academia, as well as the relationships between academia and the world around. Resonating well with our discussions above, they highlight the need to challenge dominant funding traditions, to find new ways of relating to non-academics, and to not only produce visions about just energy futures, but to work actively to translate these into practice as well as highlighting whose responsibilities it is to effectuate these practices.

Jasanoff (2018) formulates an agenda that resembles that promoted by Johan Schot and his colleagues working on transformative innovation policy. Like Schot and Kanger (2018), she traces the roots of contemporary sustainability challenges to early enlightenment thinking and an evergrowing confidence that science and innovation can resolve all problems. Current science and innovation geared towards producing low-carbon energy futures, she points out, are formulated in very narrow ways, and are typically formulated by the already well-off. In working to advance transitions in the years ahead, she suggests mobilizing four "technologies of humility", which are intended both to sensitize us to the relationship between problems in the world and policy, and to humanize unfolding transitions. These technologies are: (1) Framing, that is, the foundations and focus of our scientific endeavours and innovation activities. As an example, should we focus on improving the physical properties of energy systems, or should we rather emphasize improving the lives of those disrupted by global change? (2) Vulnerability, especially through a focus on how vulnerabilities are shaped by history, place, class and social connectedness (3) Distribution, which entails asking questions about how policies and innovation affect countries, regions and people differently, and how 
to bring the voices of those that tend to be marginalized into the expertheavy negotiations about which energy futures to embark on or promote (4) Learning, which she argues is currently constrained by the frames imposed on transition activity, and hence needs to be opened to ambiguity in order to make room for more thorough reflection on societal wide experience, and the strength and weaknesses of different approaches.

The above discussion signals a stream of contemporary critique against current innovation systems and innovation policies and their ability to produce the sorts of outcomes that are needed considering the overwhelming climate and sustainability challenges. We sympathize with these criticisms. Nevertheless, we have throughout this book discussed several pilot and demonstration projects, where we see significant potential for transformative change. In part, this can be attributed to the fact that the reach of innovation policy is not all encompassing, and that sometimes current dominant innovation policy and the rationalities within them can be enrolled and mobilized for other causes than those visible at face value. Further, we have seen examples of actors such as large companies, consulting electricians, citizens and policy makers who all in different ways take part in pilot and demonstration projects and that in doing so mobilize a wide repertoire of social, political, technological and economic goals and strategies to advance transitions. We have also seen how material elements might enable new forms of participation and new forms of politics. Hence, as we now turn to the final and concluding paragraphs of this book, we want to remain critical, while highlighting the hopeful potential of doing things differently.

\section{Conclusion: Democratic InNovation FOR INCLUSIVE TRANSFORMATION}

Through this book, we have shed light on the role of pilot and demonstration projects in emerging energy and mobility transitions. On the one hand, we have discussed how such activities emerge, which resources are mobilized in their production and which roles they take on both in transition processes and in wider societal changes. This entailed a focus on processes and practices of scaling up, and crucially, on the politics of such projects. Given that such projects are political in character we continued to discuss what this entailed, how such politics are enacted through processes of orchestration, and how such projects might open for new 
materialized forms of participation and energy citizenship. Building from a critical discussion on the relationship between innovation policy and pilot activities, we now turn to formulate a set of insights that can be gleaned from our discussions.

First, from a co-productionist and ecological perspective rooted in STS, it becomes clear that the responsibilities of achieving systemic transformations are distributed in society and amongst actors that are spread out across levels, sectors and domains of society. This means that transformative change requires innovation policies that target a broad set of issues, actors and societal domains. Second, this observation calls for very ambitious goals in terms of inclusively working to engage societal actors in transition work. This means looking beyond the types of actors that are presently active in building consortiums, developing, testing and using technologies, to actively ask who are implicated by the proposed developments and to work actively to amplify the voices heard and included in such activities.

Third, inclusivity not only entails the enrolment of large amounts of actors in the pursuit of specific technological goals. Inclusivity also entails looking beyond the dominant forms of knowledge, to mobilize insights from different disciplines as well as from citizens and other implicated actors when framing and formulating questions. Further, it entails working actively to mobilize epistemic and practical diversity in processes of innovation. Finally, it entails systematically pushing to ensure diverse outcomes. Fourth, and building on the latter point, is the importance of producing innovation policy and pilot projects that formulates distinctly social goals to go alongside the technological ambitions, or indeed to conduct pilots where experimenting with and transforming the social is the end goal. Such goals can relate, for example, to the use of technologies, but they could also be much broader, for example formulated as a vision for how policy and innovation will contribute to a more equitable and just society.

Fifth, participation and engagement are key social aspects of many pilot and demonstration projects and should be given priority. Working actively to orchestrate modes of participation that goes beyond the consumer role or accepting ready-made technologies should be prioritized. Sixth, and relatedly, the material elements mobilized in pilot and demonstration projects (e.g. individual technologies, infrastructures), are political. Innovators and designers could therefore embrace and experiment with 
how to exploit this fact rather than attempt to disguise technologies as neutral market devices or objective commodities.

Seventh, and building on the above points, innovation policy should embrace social and normative goals about the state of future societies, and work to nurture, stimulate and shield the emergence of organizations, movements and networks that promotes sustainable social change in similar ways that they currently nurture new technologies.

Eighth, the fact that the responsibility for enacting transitions is distributed, that a wide array of actors, and traditions of knowledge production will be involved, also means that transitions will have to come to terms with a wide range of interests and rationalities. This means conflict and controversy will be the norm, rather than the exception. Transition scholars have tended to emphasize the need to build shared visions, alignment and consensus in processes of transition. This will likely not be feasible if the end goal is transformative change. Experimenting with modes of engagement and participation that unties, reveals and cultivates conflicts could be a viable option.

In sum, the eight insights highlighted above are intended to illustrate a way forward from what Colette Bos (2014) pointed to as steering through big words. Big words can become empty signifiers, and the above is an attempt to make signifiers like 'inclusion' and 'democracy' more tangible in the context of energy transitions in general, and pilot and demonstration projects, in particular. As we move forward as scholars and practitioners, this list is also humbling. It illustrates the massive challenges ahead of us, while also pointing to some relatively concrete steps we could take and build further on in future energy transitions endeavours. Many futures are at stake, and many futures can be produced. Pilot and demonstration projects play a vital role in the shaping of our futures and will continue to do so for a long time. Which roles they will play, is still an open question, but also something for us as social scientist, STS and/or transition scholars and researchers to shape, contest, challenge and rethink.

\section{REFERENCES}

Akrich, M. (1992). The de-scription of technical objects. In W. Bijker \& J. Law (Eds.), Shaping technology/Building society: Studies in socio-technological change. MIT Press.

Ballo, I. F. (2015). Imagining energy futures: Sociotechnical imaginaries of the future Smart Grid in Norway. Energy Research \& Social Science, 9, 9-20. 
Bos, C., Walhout, B., Peine, A., \& van Lente, H. (2014). Steering with big words: Articulating ideographs in research programs. Journal of Responsible Innovation, 1(2), 151-170.

Chilvers, J., Pallett, H., \& Hargreaves, T. (2018). Ecologies of participation in socio-technical change: The case of energy system transitions. Energy Research o Social Science, 42, 199-210.

Delina, L. L., \& Sovacool, B. K. (2018). Of temporality and plurality: An epistemic and governance agenda for accelerating just transitions for energy access and sustainable development. Current Opinion in Environmental Sustainability, 34, 1-6.

Eaton, W. M., Burnham, M., Hinrichs, C. C., \& Selfa, T. (2017). Bioenergy experts and their imagined "obligatory publics" in the United States: Implications for public engagement and participation. Energy Research \& Social Science, 25, 65-75.

European Commission. (2017). The Strategic Energy Technology (SET) Plan. Accessed from: https://setis.ec.europa.eu/sites/default/files/setis\%20reports/ 2017_set_plan_progress_report_0.pdf

Fjellså, I., Silvast, A., \& Skjølsvold, T. M. (forthcoming). Fair flexibility? Capabilities and framings of user flexibility in the electricity grid2. Under review in Environmental Innovations and Societal Transitions.

Foulds, C., \& Robison, R. (2018). Advancing energy policy. Cham: Palgrave Pivot. Funtowicz, S. O., \& Ravetz, J. R. (1995). Science for the post normal age. In Perspectives on ecological integrity (pp. 146-161). Dordrecht: Springer.

Geels, F. W. (2002). Technological transitions as evolutionary reconfiguration processes: A multi-level perspective and a case-study. Research Policy, 31(8-9), $1257-1274$.

Gibbons, M. (Ed.). (1994). The new production of knowledge: The dynamics of science and research in contemporary societies. Sage.

Goulden, M., Bedwell, B., Rennick-Egglestone, S., Rodden, T., \& Spence, A. (2014). Smart grids, smart users? The role of the user in demand side management. Energy Research \& Social Science, 2, 21-29.

Gram-Hanssen, K., \& Darby, S. J. (2018). "Home is where the smart is"? Evaluating smart home research and approaches against the concept of home. Energy Research \& Social Science, 37, 94-101.

Hopkins, D., \& Higham, J. E. (Eds.). (2016). Low carbon mobility transitions. Goodfellow Publishers Ltd.

Ingeborgrud, L., Heidenreich, S., Ryghaug, M., Skjølsvold, T. M., Foulds, C., Robison, R., ... Mourik, R. (2020). Expanding the scope and implications of energy research: A guide to key themes and concepts from the Social Sciences and Humanities. Energy Research of Social Science, 63, 101398.

Jasanoff, S. (2018). Just transitions: A humble approach to global energy futures. Energy Research \& Social Science, 35, 11-14. 
Jenkins, K., Sovacool, B. K., \& McCauley, D. (2018). Humanizing sociotechnical transitions through energy justice: An ethical framework for global transformative change. Energy Policy, 117, 66-74.

Jenkins, K. E., Stephens, J. C., Reames, T. G., \& Hernández, D. (2020). Towards impactful energy justice research: Transforming the power of academic engagement. Energy Research os Social Science, 67, 101510.

Nowotny, H., Scott, P. B., \& Gibbons, M. T. (2013). Re-thinking science: Knowledge and the public in an age of uncertainty. John Wiley \& Sons.

Oudshoorn, N. E., \& Pinch, T. (2003). How users matter: The co-construction of users and technologies. MIT Press.

Øverland, I., \& Sovacool, B. K. (2020). The misallocation of climate research funding. Energy Research os Social Science, 62, 101349.

Powells, G., \& Fell, M. J. (2019). Flexibility capital and flexibility justice in smart energy systems. Energy Research o Social Science, 54, 56-59.

Rip, A., Misa, T. J., \& Schot, J. (Eds.). (1995). Managing technology in society. London: Pinter Publishers.

Ryghaug, M., Ornetzeder, M., Skjølsvold, T. M., \& Throndsen, W. (2019). The role of experiments and demonstration projects in efforts of upscaling: an analysis of two projects attempting to reconfigure production and consumption in energy and mobility. Sustainability, $11(20), 5771$.

Ryghaug, M., Skjølsvold, T. M., \& Heidenreich, S. (2018). Creating energy citizenship through material participation. Social Studies of Science, 48(2), 283-303.

Ryghaug, M., \& Toftaker, M. (2016). Creating transitions to electric road transport in Norway: The role of user imaginaries. Energy Research \& Social Science, $17,119-126$.

Schot, J., \& Kanger, L. (2018). Deep transitions: Emergence, acceleration, stabilization and directionality. Research Policy, 47(6), 1045-1059.

Schot, J., \& Steinmueller, W. E. (2018). Three frames for innovation policy: R\&D, systems of innovation and transformative change. Research Policy, 47(9), $1554-1567$.

Schot, J. W. (1992). Constructive technology assessment and technology dynamics: The case of clean technologies. Science, Technology, \& Human Values, $17(1), 36-56$.

Skjølsvold, T. M. (2012). Publics in the pipeline. In N. Möllers \& K. Zachmann (Eds.), Past and present energy societies. Bielefeld: Transcript Verlag.

Skjølsvold, T. M. (2014). Back to the futures: Retrospecting the prospects of smart grid technology. Futures, 63, 26-36.

Skjølsvold, T. M., \& Ryghaug, M. (2015). Embedding smart energy technology in built environments: A comparative study of four smart grid demonstration projects. Indoor and Built Environment, 24(7), 878-890.

Skjølsvold, T. M., Fjellså, I. F., \& Ryghaug, M. (2019). Det fleksible mennesket 2.0. Norsk sosiologisk tidsskrift, 3(03), 191-208. 
Skjølsvold, T. M., \& Lindkvist, C. (2015). Ambivalence, designing users and user imaginaries in the European smart grid: Insights from an interdisciplinary demonstration project. Energy Research \& Social Science, 9, 43-50.

Skjølsvold, T. M., Throndsen, W., Ryghaug, M., Fjellså, I. F., \& Koksvik, G. H. (2018). Orchestrating households as collectives of participation in the distributed energy transition: New empirical and conceptual insights. Energy Research \& Social Science, 46, 252-261.

Sovacool, B., Hess, D. J., Amir, S., Geels, F. W., Hirsh, R., Medina, L. R., ... Yearley, S. (2020). Sociotechnical agendas: Reviewing future directions for energy and climate research. Energy Research and Social Science, 70, 1-35.

Sovacool, B. K. (2014). What are we doing here? Analyzing fifteen years of energy scholarship and proposing a social science research agenda. Energy Research of Social Science, 1, 1-29.

Stilgoe, J., Owen, R., \& Macnaghten, P. (2013). Developing a framework for responsible innovation. Research Policy, 42(9), 1568-1580.

Strengers, Y. (2013). Smart energy technologies in everyday life: Smart Utopia?. Cham: Springer.

Strengers, Y. (2014). Smart energy in everyday life: are you designing for resource man?. Interactions, 21(4), 24-31.

Suboticki, I., Świątkiewicz-Mośny, M., Ryghaug, M., \& Skjølsvold, T. M. (2019). Inclusive engagement in Energy with special focus on low carbon transport solutions. Scoping workshop report. Cambridge: Energy-SHIFTS.

Throndsen, W., \& Ryghaug, M. (2015). Material participation and the smart grid: Exploring different modes of articulation. Energy Research \& Social Science, $9,157-165$.

Valkenburg, G. (2020). Consensus or contestation: Reflections on governance of innovation in a context of heterogeneous knowledges. Science, Technology and Society, https://doi.org/10.1177/0971721820903005.

Von Schomberg, R. (2013). A vision of responsible research and innovation. In Responsible innovation: Managing the responsible emergence of science and innovation in society (pp. 51-74). Wiley.

Wallsten, A., \& Galis, V. (2019). The discreet charm of activeness: The vain construction of efficient smart grid users. Journal of Cultural Economy, 12(6), 571-589.

Weiland, S., Bleicher, A., Polzin, C., Rauschmayer, F., \& Rode, J. (2017). The nature of experiments for sustainability transformations: A search for common ground. Journal of Cleaner Production, 169, 30-38.

Wilson, C., Grubler, A., Gallagher, K. S., \& Nemet, G. F. (2012). Marginalization of end-use technologies in energy innovation for climate protection. Nature Climate Change, 2(11), 780-788. 
Winskel, M. (2018). The pursuit of interdisciplinary whole systems energy research: Insights from the UK Energy Research Centre. Energy Research \& Social Science, 37, 74-84.

Winskel, M., \& Radcliffe, J. (2014). The rise of accelerated energy innovation and its implications for sustainable innovation studies: A UK perspective. Science \& Technology Studies, 27, 8-33.

Woolgar, S. (1990). Configuring the user: The case of usability trials. The Sociological Review, 38(1_suppl), 58-99.

Zwart, H., Landeweerd, L., \& Van Rooij, A. (2014). Adapt or perish? Assessing the recent shift in the European research funding arena from 'ELSA' to 'RRI'. Life Sciences, Society and Policy, 10(1), 1-19.

Open Access This chapter is licensed under the terms of the Creative Commons Attribution 4.0 International License (http://creativecommons.org/licenses/ by $/ 4.0 /$ ), which permits use, sharing, adaptation, distribution and reproduction in any medium or format, as long as you give appropriate credit to the original author(s) and the source, provide a link to the Creative Commons licence and indicate if changes were made.

The images or other third party material in this chapter are included in the chapter's Creative Commons licence, unless indicated otherwise in a credit line to the material. If material is not included in the chapter's Creative Commons licence and your intended use is not permitted by statutory regulation or exceeds the permitted use, you will need to obtain permission directly from the copyright holder.

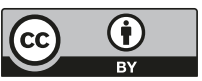

